Check for updates

Cite this: RSC Adv., 2017, 7, 43255

Received 30th July 2017

Accepted 1st September 2017

DOI: $10.1039 / c 7 r a 08390 d$

rsc.li/rsc-advances

\section{Fabrication of nanoporous copper with tunable ligaments and promising sonocatalytic performance by dealloying $\mathrm{Cu}-\mathrm{Y}$ metallic glasses $\uparrow$}

\begin{abstract}
Ning Wang, Ye Pan, (D)* Shikai Wu, Enming Zhang and Weiji Dai
Nanoporous copper (NPC) with tunable ligaments was prepared by dealloying $\mathrm{Cu}-\mathrm{Y}$ binary amorphous ribbons in sulfuric acid $\left(\mathrm{H}_{2} \mathrm{SO}_{4}\right)$ solution. The ligament size of the NPC sample synthesized by dealloying $\mathrm{Cu}_{58} \mathrm{Y}_{42}$ metallic glasses $(237 \mathrm{~nm})$ is much smaller than the one by dealloying $\mathrm{Cu}_{72} \mathrm{Y}_{28}(406 \mathrm{~nm})$. This result reveals that the microstructure of NPC can be strongly influenced by the alloy composition of precursor alloys. Then, NPC with different microstructures were applied in the sono-catalytic degradation of methyl orange (MO) dye. NPC produced by dealloying $\mathrm{Cu}_{58} \mathrm{Y}_{42}$ metallic glasses displayed superior sonocatalytic activity compared to commercial copper foil and the sample by dealloying $\mathrm{Cu}_{72} \mathrm{Y}_{28}$. The mechanism of the sono-Fenton-like process of NPC can be explained by being due to a combination of $\mathrm{Cu}$ ligament, $\mathrm{H}_{2} \mathrm{O}_{2}$ and ultrasound. In addition, the influence of the dealloying conditions (acid concentration, temperature and leaching time) on the ligament size of NPC was evaluated comprehensively, which could provide meaningful insight for further fabricating NPC with more desirable morphology and higher catalytic activity.
\end{abstract}

\section{Introduction}

Textile industry wastewater with large amounts of diverse dyes can cause serious environmental problems. ${ }^{1-5}$ Thus, it is necessary to decompose these dyes to an acceptable level before they are discharged into the environment. As the most popular approach used for dye degradation, the advanced oxidation process (AOP) is proposed to solve this problem. ${ }^{6-9}$ Hydroxyl radicals $\left({ }^{\circ} \mathrm{OH}\right)$ produced in this process can effectively degrade organic dye owing to their strong oxidizing and non-selective nature. ${ }^{10-12}$ Among all AOPs, a photocatalytic method is usually adopted to produce reactive species with the purpose of removing contaminants from water. ${ }^{13,14}$ However, it is difficult to decompose the opaque or translucent dye wastewater by light irradiation because the penetrating ability of the light is limited, it is too hard for the light to penetrate such solutions, thus leading to low penetrating depth (only several millimeters). ${ }^{\mathbf{1 , 1 5}}$ Considering the advantage of having strong penetrating ability for any medium, ${ }^{\mathbf{1 6}}$ the ultrasonic irradiation is introduced. The ultrasound process has been considered as an advanced technology since 1990, which can operate easily and degrade non-transparent or low-transparent dyes availably. ${ }^{\mathbf{1 7 , 1 8}}$ The main mechanism of ultrasonic process can be understood

School of Materials Science and Engineering, Southeast University, Jiangsu Key Laboratory for Advanced Metallic Materials, Nanjing 211189, P. R. China. E-mail: panye@seu.edu.cn; Fax: +86 25 52090681; Tel: +86 2552090681

$\dagger$ Electronic supplementary information (ESI) available. See DOI: 10.1039/c7ra08390d based on the acoustic cavitations, which involve the formation (nucleation), growth (expansion) and collapse (implosion) of cavitation bubbles. ${ }^{19-21}$ Among them, implosive collapse of cavitation bubbles can produce local "hot spots" with high temperatures (several thousand $\mathrm{K}$ ) and high pressures (some $10 \mathrm{Mpa}) .{ }^{20,22-25}$ As a result, water $\left(\mathrm{H}_{2} \mathrm{O}\right)$ molecules are cleaved to highly reactive hydroxyl radicals $\left({ }^{\circ} \mathrm{OH}\right){ }^{26-28}$ Nevertheless, the number of ${ }^{\circ} \mathrm{OH}$ generated by the pyrolysis of $\mathrm{H}_{2} \mathrm{O}$ is limited. To produce more $\mathrm{OH}$, there should be some catalysts in the degradation process, which can act as the nucleus of cavitation bubbles. ${ }^{29-31}$ In view of this, a high efficient sono-Fenton-like process, namely, a combination of ultrasound and hydrogen peroxide $\left(\mathrm{H}_{2} \mathrm{O}_{2}\right)$ with transition metal was carried out. The Fenton system uses transition metal or transition metal ions to react with hydrogen peroxide, producing hydroxyl radicals to decompose the organic compounds. ${ }^{32}$ However, traditional metal foil has a very small specific surface area, leading to low catalytic activity, and metal powder is hard to be recycled, which requires much effort for separation. Therefore, fabrication of a catalytic material with both large specific surface area and high recovery is necessary. Nanoporous metal has recently attracted more and more interest due to unique threedimensional (3D) bi-continuous ligament-channel structure, which has shown promising application in a wide variety of fields of catalysis, sensors, actuators, fuel cells, microfluidic flow controllers and surface plasmon resonance, ${ }^{33-38}$ etc. Compared with the powder, the nanoporous material can connect all the fine ligaments into one complete set, which is very favorable for its recovery. Moreover, 3D bi-continuous 
nanostructure indicates that nanoporous metal has enhanced catalytic activity owing to its large special surface area. Consequently, nanoporous metals can be a good choice to construct sono-Fenton-like catalytic system.

Dealloying, ${ }^{39}$ a simple chemical process of selective dissolution of the less noble elements out of a precursor alloy, has been demonstrated to be a promising strategy for fabricating nanoporous metals. Compared to crystalline alloys, metallic glasses were regarded as the more ideal precursors. It is because that the metallic glasses are free from crystallographic defects (mostly grain boundaries, dislocations and segregations) and exhibit a unique disordered atomic structure, ${ }^{\mathbf{4 0 , 4 1}}$ which is conducive to preparing uniform nanoporous material. Rizzi ${ }^{\mathbf{4 2}}$ have synthesized monolithic nanoporous gold (NPG) with a ligament size of 100-130 $\mathrm{nm}$ through dealloying of a $\mathrm{Au}_{40} \mathrm{Cu}_{28} \mathrm{Si}_{20} \mathrm{Ag}_{7} \mathrm{Pd}_{5}$ glassy alloys. Jin ${ }^{43}$ have fabricated homogeneous nanoporous silver (NPS) with tunable ligament sizes (30-90 $\mathrm{nm}$ ) via chemical dealloying $\mathrm{Ag}_{60.5} \mathrm{Ca}_{39.5}$ amorphous ribbons. Dan ${ }^{44}$ have prepared uniform nanoporous copper (NPC) with the ligament width of $46-338 \mathrm{~nm}$ by dealloying $\mathrm{Cu}-\mathrm{Ti}$ metallic glasses. The results suggest that amorphous alloys are readily available for synthesizing uniform nanoporous metals by dealloying.

In this work, nanoporous copper (NPC) with tunable ligament sizes has been prepared by dealloying $\mathrm{Cu}_{100-x} \mathrm{Y}_{x}(x=28$ and 42 at\%) binary metallic glasses in dilute $\mathrm{H}_{2} \mathrm{SO}_{4}$ solution (the alloy compositions are chosen near eutectic points to aim at obtaining the fully amorphous ${ }^{45}$ ). Novel $\mathrm{Cu}-\mathrm{Y}$ binary metallic glasses are very ideal precursors for dealloying from an electrochemical perspective: the standard electrode potentials of $\mathrm{Y}$ and $\mathrm{Cu}$ differ as much as $2.714 \mathrm{~V}(-2.372 \mathrm{~V}$ vs. the standard hydrogen electrode (SHE) for $\mathrm{Y} / \mathrm{Y}^{3+}$ and $0.342 \mathrm{~V}$ vs. SHE for $\mathrm{Cu} / \mathrm{Cu}^{2+}$ ), which promises to be a large driving force for selective leaching of $\mathrm{Y}$ from $\mathrm{Cu}-\mathrm{Y}$ amorphous alloys in dilute $\mathrm{H}_{2} \mathrm{SO}_{4}$ solution. Then, NPC with different microstructures were applied in the sono-catalytic degradation of methyl orange (MO) dye. The objectives were to investigate the relationship between the structure of NPC and corresponding sono-Fenton-like catalytic properties, and understand the effects of dye concentration, temperature and output power on MO degradation in the presence of NPC. In addition, the influences of the acid concentration, temperature and leaching time on the ligament size of NPC were evaluated systematically, which could provide abundant information and lay a theoretic basis for further designing NPC with more suitable ligament size and higher catalytic activity. To the best of our knowledge, there is no report about the effect of the ligament size of NPC on its sono-Fentonlike catalytic performance and the fabrication of $\mathrm{Cu}-\mathrm{Y}$ binary metallic glasses has not been reported so far.

\section{Experimental}

\section{Synthesis}

The ingots of $\mathrm{Cu}_{100-x} \mathrm{Y}_{x}(x=28$ and 42 at\%) were prepared by arc melting a mixture of pure $\mathrm{Cu}$ and $\mathrm{Y}$ elements with purities above $99.99 \%$ in a Ti-gettered argon atmosphere, followed by a single roller spinning to obtain amorphous ribbons with a width of $2 \mathrm{~mm}$ and a thickness of $20-30 \mu \mathrm{m}$.

Chemical dealloying $\mathrm{Cu}-\mathrm{Y}$ amorphous ribbons was performed in dilute $\mathrm{H}_{2} \mathrm{SO}_{4}$ aqueous solution. In order to evaluate the effect of chemical composition on the morphologies of the resulting $\mathrm{NPC}, \mathrm{Cu}_{72} \mathrm{Y}_{28}$ and $\mathrm{Cu}_{58} \mathrm{Y}_{42}$ glassy ribbons were used, they were dealloyed in $1 \mathrm{M} \mathrm{H}_{2} \mathrm{SO}_{4}$ solution at $333 \mathrm{~K}$ for $90 \mathrm{~min}$. Moreover, the different concentration of $\mathrm{H}_{2} \mathrm{SO}_{4}$ electrolytic solution was adopted to estimate the influence of acid concentration on the microstructure of NPC, i.e. 0.2, 0.4, 1, 2 M, respectively. $\mathrm{Cu}_{58} \mathrm{Y}_{42}$ amorphous ribbons were leached in the acid solution with the difference concentration at $323 \mathrm{k}$ for $90 \mathrm{~min}$. Besides, the effect of temperature on the ligament growth of NPC obtained from $\mathrm{Cu}_{58} \mathrm{Y}_{42}$ glassy ribbons was investigated by leaching them in $1 \mathrm{M} \mathrm{H}_{2} \mathrm{SO}_{4}$ aqueous solution for $90 \mathrm{~min}$ at various temperatures of 323,333 and $343 \mathrm{~K}$. Furthermore, the influence of immersion time on nanoporous structure was also studied. $\mathrm{Cu}_{58} \mathrm{Y}_{42}$ amorphous ribbons were leached in $1 \mathrm{M} \mathrm{H}_{2} \mathrm{SO}_{4}$ electrolytic solution at $333 \mathrm{~K}$ for different immersion time $(60,120$ and $240 \mathrm{~min})$. After dealloying, all the ribbons were rinsed with distilled water and dehydrated alcohol, then kept in vacuum chamber until characterizations.

\section{Characterization}

The phase composition of the as-spun and as-dealloyed ribbons was characterized by X-ray diffraction (XRD) using a D8-Discover diffractometer with $\mathrm{Cu}-\mathrm{K}_{\alpha}$ radiation $(\lambda=1.5406 \AA)$, the accelerating voltage and the applied current were $30 \mathrm{kV}$ and $20 \mathrm{~mA}$, respectively. The microstructures of obtained NPC specimens were investigated by FEI-3D scanning electron microscopy (SEM) operating with an accelerating voltage of $10 \mathrm{kV}$, and transmission electron microscopy (TEM) using a G2-20 instrument operating at $300 \mathrm{kV}$. The size of the ligament was statistically measured by a single length chord method over 200 sites of SEM morphologies. In addition, a Quantachrome Autosorb-IQ2 analyzer was used to measure the specific surface area $\left(S_{\mathrm{BET}}\right)$ of the NPC samples.

\section{Sonocatalytic measurements}

The sonocatalytic activities of the samples were estimated by the degradation of MO. The initial MO concentration was $20 \mathrm{mg} \mathrm{L}{ }^{-1}$. In this experiment, $100 \mathrm{~mL}$ MO solution, $50 \mathrm{mg}$ catalyst of NPC and $0.5 \mathrm{~mL} 30 \mathrm{wt} \%$ hydrogen peroxide $\left(\mathrm{H}_{2} \mathrm{O}_{2}\right)$ were put into a $250 \mathrm{~mL}$ erlenmeyer flask. Then, the degradation reactions were conducted in a serial-ultrasonic apparatus (KH-300DB, Kunshan Ultrasonic Apparatus Company, China) with a frequency of $40 \mathrm{kHz}$ and output power of $4800 \mathrm{~mW} \mathrm{~cm}^{-2}$ at 333 K. Prior to irradiation, the whole suspension was stirred for $30 \mathrm{~min}$ to ensure the establishment of the adsorptiondesorption equilibrium. Afterwards, $3 \mathrm{~mL}$ of the suspension was extracted every $5 \mathrm{~min}$ during the sonocatalytic process to test the residual concentrations of MO. The concentration of MO solution was evaluated by measuring the change in maximum absorbance through TU-1810 UV-vis spectrophotometer. The absorbance peak at $464 \mathrm{~nm}$ was selected, and the 
residual concentration was obtained by evaluating the intensity ratio between the residual and original MO solutions.

\section{Results and discussion}

\section{Effects of alloy compositions on the microstructure of NPC}

Fig. 1a shows XRD patterns of $\mathrm{Cu}_{100-x} \mathrm{Y}_{x}(x=28$ and 42 at $\%)$ ribbons. The ribbons all present a broad diffraction peak in their patterns corresponding to a fully amorphous structure. Fig. $1 \mathrm{~b}$ displays the XRD patterns of $\mathrm{Cu}-\mathrm{Y}$ amorphous ribbons subjected to immersion in $1 \mathrm{M} \mathrm{H}_{2} \mathrm{SO}_{4}$ solution at $333 \mathrm{~K}$ for $90 \mathrm{~min}$. It can be seen that the characteristic broad patterns of the samples disappear completely and crystalline diffraction peaks of (111), (200) and (220) appear significantly. All these peaks can be indexed to face centered cubic copper $(f c c \mathrm{Cu})$ with lattice parameter of $a=3.615 \AA$ (JCPDS card no. 04-0836).

Fig. 2a and $\mathrm{b}$ presents the SEM images of the samples by dealloying $\mathrm{Cu}-\mathrm{Y}$ binary metallic glasses $\left(\mathrm{Cu}_{72} \mathrm{Y}_{28}\right.$ and $\left.\mathrm{Cu}_{58} \mathrm{Y}_{42}\right)$ in $1 \mathrm{M} \mathrm{H}_{2} \mathrm{SO}_{4}$ aqueous solution at $333 \mathrm{~K}$ for $90 \mathrm{~min}$. The samples exhibited uniform 3D bi-continuous nanostructure. Combining this with the results of XRD can confirm that NPC has been successfully synthesized. For convenience, the NPC samples prepared by dealloying $\mathrm{Cu}_{72} \mathrm{Y}_{28}$ and $\mathrm{Cu}_{58} \mathrm{Y}_{42}$ metallic glasses are denoted as the NPC-72 and NPC-58 sample, respectively. It is observed that the ligament size of the NPC-58 sample $(237 \mathrm{~nm})$ is much smaller than that of NPC-72 $(406 \mathrm{~nm})$. This is because that the increase in $\mathrm{Cu}$ content favors the growth of ligaments. ${ }^{46}$ The results reveal that the microstructure of NPC can be strongly influenced by the alloy compositions of precursor alloys. In addition, the EDS results (Fig. 2c-d) show that the alloy compositions of the dealloying samples consist almost entirely of $\mathrm{Cu}$ element, implying that $\mathrm{Y}$ has been completely leached out of the precursors and $\mathrm{Cu}$ remains to form a framework of the resulting nanoporous structure. The results are in accordance with the results of XRD.

Fig. 3a and b depicts the TEM images of the NPC samples. The bi-continuous pore-to-ligament structure is clearly visible. It can also be seen that the NPC-58 sample has much finer ligament structure than NPC-72, which agrees well with SEM images. In general, material with finer microstructure possesses larger specific surface area. Therefore, the specific surface area of the NPC-58 sample is much larger than that of NPC-72 (confirmed by BET method and displayed in Table 1). The HRTEM lattice fringe images of the NPC samples can be observed in Fig. $3 \mathrm{c}$ and d. The interplanar spacing of the samples is determined to be $0.209 \mathrm{~nm}$, which is associated with the $\{111\}$ planes of $f c c \mathrm{Cu}$.

\section{Sonocatalytic activities}

The experiment of sonocatalytic degradation of methyl orange (MO) dye was carried out to explore the catalytic performance of NPC. The temporal absorption spectral changes of MO dye in sono-degradation over the NPC-72 sample are shown in Fig. 4a. The result demonstrates that the intensity of the peak decreases quickly with the increasing of irradiation time, which implies that MO can be effectively decomposed by NPC. Fig. $4 \mathrm{~b}$ is the image of the solution under ultrasound irradiation for different time. The solution was gradually faded with increasing the reaction time and it was similar to water when the irradiation sustain for $30 \mathrm{~min}$. Wang ${ }^{47}$ reported sonocatalytic degradation of methyl orange in the presence of $\mathrm{TiO}_{2}$ catalysts, the $\mathrm{MO}$ dye was decomposed within 150 min. In this experiment, the degradation of MO can be finished within 30 min, suggesting that NPC is much more efficient for sonocatalytic degradation than traditional catalyst (e.g., $\left.\mathrm{TiO}_{2}\right)$. Fig. $4 \mathrm{~b}$ shows $\mathrm{MO}$ degradation rate as a function of reaction time. The MO solution with commercial copper foil degraded at a relative slow rate, only $35.2 \%$ was degraded within $15 \mathrm{~min}\left(t_{1 / 2}\right.$ of $\left.30 \mathrm{~min}\right)$, while $65.7 \%$ and $83.4 \%$ of MO was decomposed over the NPC-72 and NPC-58 sample, respectively, which reveals that the sonocatalytic performance of NPC is much better than that of copper foil. The enhanced catalytic performance of NPC can be ascribed to 3D bi-continuous nanoporous structure, fine $\mathrm{Cu}$ ligaments with good dispersion and large special surface area. Thus, NPC can be a very ideal choice to construct sono-Fenton-like catalytic system. In Fig. 4c, a linear relationship between $\ln \left(C / C_{0}\right)$ and irradiation time suggests that the sonocatalytic degradation process obeys pseudo-first-order kinetics. The values of the reaction rate constant can be calculated based on the Langmuir-Hinshelwood model: ${ }^{49,50}$ a

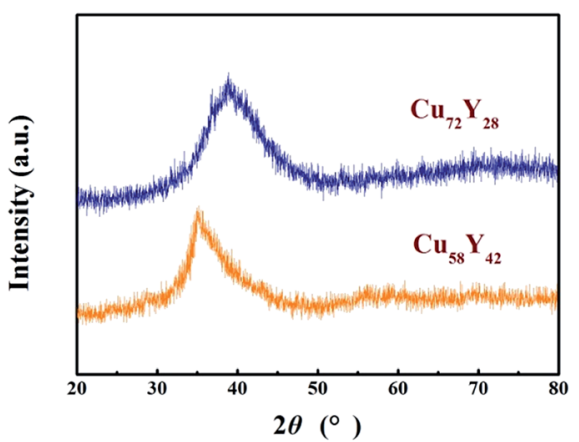

b

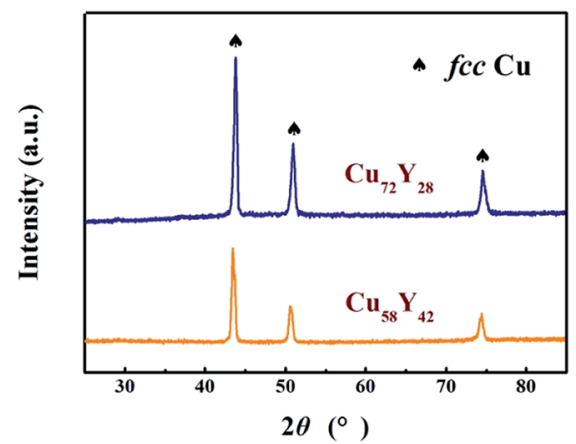

Fig. 1 XRD patterns of (a) $\mathrm{Cu}-\mathrm{Y}$ binary metallic glasses and (b) the corresponding samples after dealloying in $1 \mathrm{M} \mathrm{H}_{2} \mathrm{SO}_{4}$ aqueous solution at $333 \mathrm{~K}$ for $90 \mathrm{~min}$. 

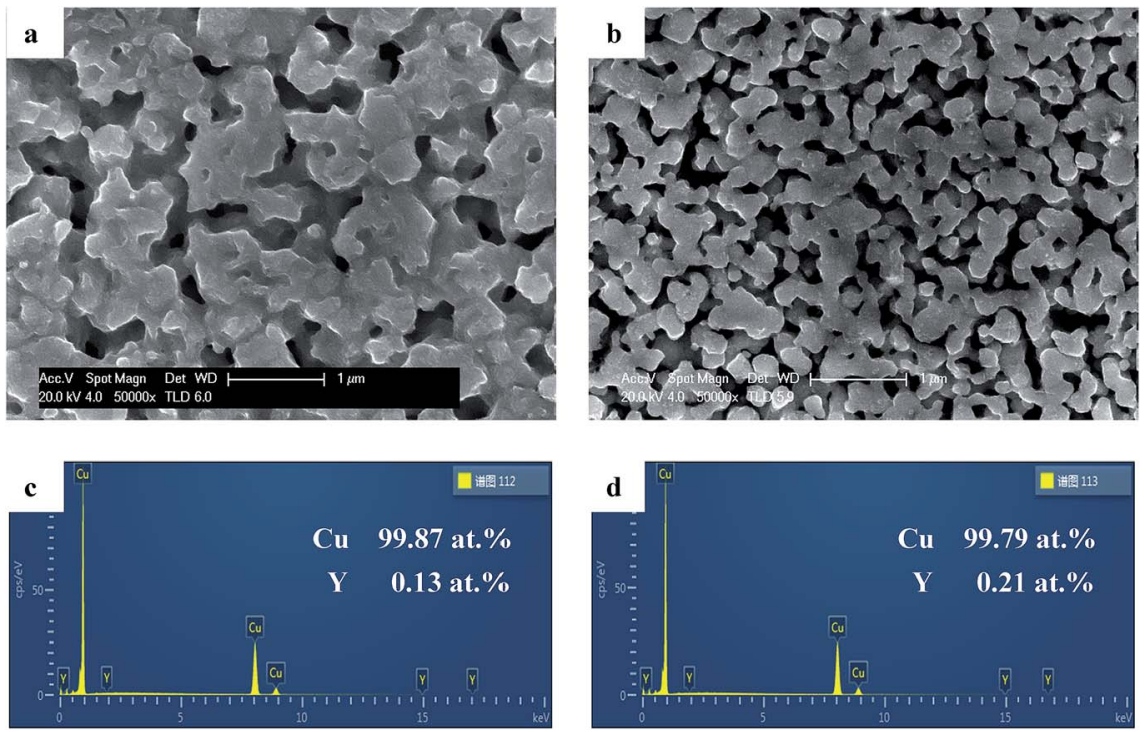

Fig. 2 SEM images of NPC by dealloying (a) $\mathrm{Cu}_{72} \mathrm{Y}_{28}$ and (b) $\mathrm{Cu}_{58} \mathrm{Y}_{42}$ binary metallic glasses in $1 \mathrm{M} \mathrm{H}_{2} \mathrm{SO}_{4}$ aqueous solution at $333 \mathrm{~K}$ for 90 min. Typical EDS spectrum of the samples: (c) NPC-72; (d) NPC-58.

$$
\ln \left(C / C_{0}\right)=-k t
$$

where $C$ is the concentration of $\mathrm{MO}$ at time $t, C_{0}$ is the initial concentration, $k$ is the apparent reaction rate constant. The $k$ values of different experiment conditions (no catalyst used, $\mathrm{Cu}$ foil used, NPC-72 used and NPC-58 used) were estimated as $0.004,0.039,0.088$ and $0.162 \mathrm{~min}^{-1}$, respectively. It is clear that NPC-58 exhibits superior sonocatalytic activity compared to the
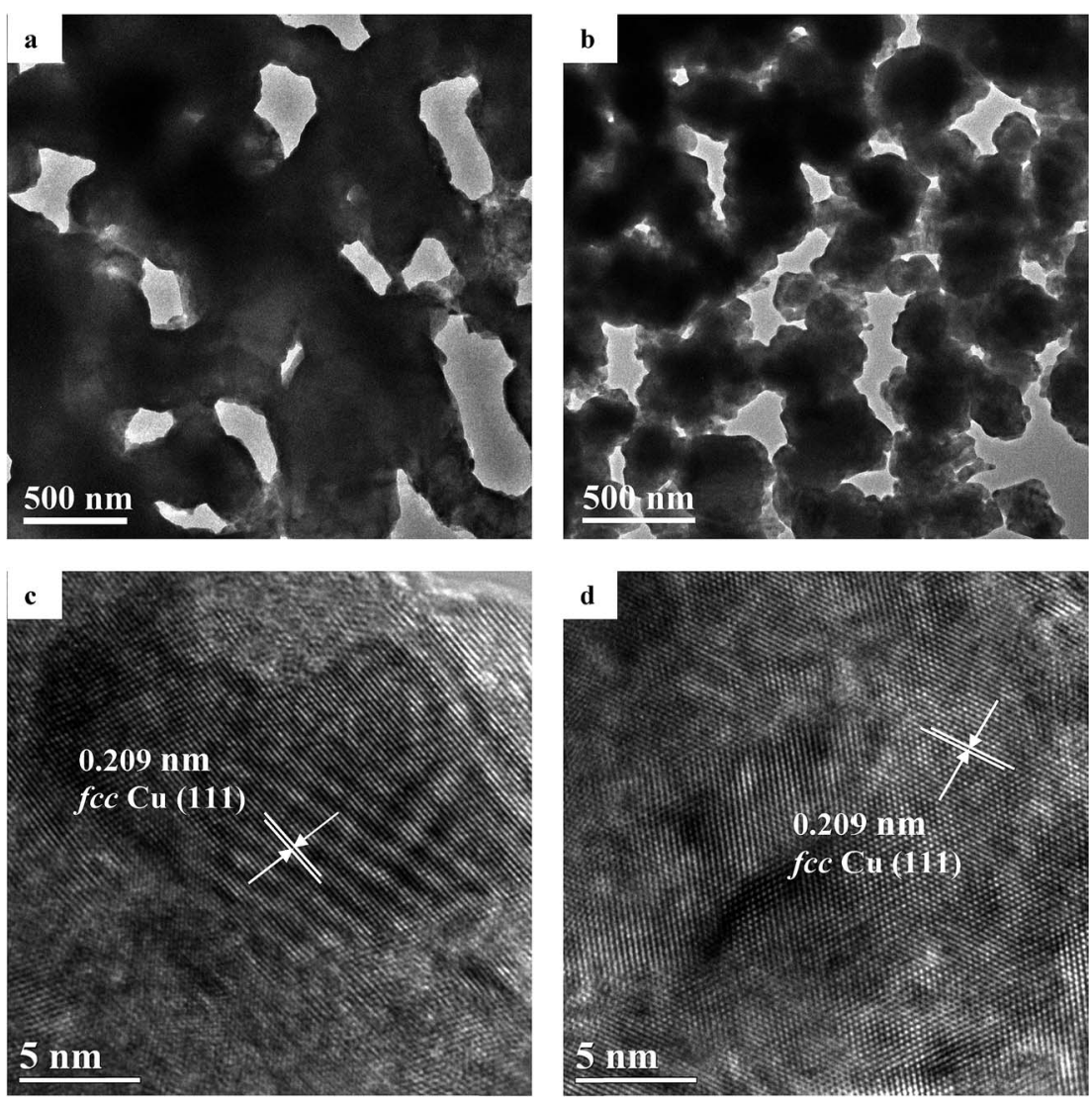

Fig. 3 TEM images of the samples: (a) NPC-72; (b) NPC-58. HRTEM lattice fringe images of the samples: (c) NPC-72; (d) NPC-58. 
Table 1 The morphological features (ligament size $(d)$, specific surface area $\left(S_{\mathrm{BET}}\right)$ and total pore volume $\left.\left(V_{\mathrm{p}}\right)\right)$ of the NPC samples

\begin{tabular}{llll}
\hline Samples & $d(\mathrm{~nm})$ & $S_{\text {BET }}\left(\mathrm{m}^{2} \mathrm{~g}^{-1}\right)$ & $V_{\mathrm{p}}$-total $\left(\mathrm{cm}^{3} \mathrm{~g}^{-1}\right)$ \\
\hline NPC-72 & $406 \pm 36.6$ & $1.88 \pm 0.51$ & 0.048 \\
NPC-58 & $237 \pm 24.3$ & $3.84 \pm 0.94$ & 0.072 \\
\hline
\end{tabular}

NPC-72 sample. The reasons can be attributed to three major ones: (1) it is known that the surface of a catalyst would be acted as the nucleus for cavitation bubbles in the sono-catalytic process. ${ }^{4}$ Hence, more nucleus can be formed on the surface of the NPC-58 sample, which has much larger specific surface area $\left(3.84 \mathrm{~m}^{2} \mathrm{~g}^{-1}\right)$ than NPC-72 $\left(1.88 \mathrm{~m}^{2} \mathrm{~g}^{-1}\right)$, thus improving the effects of cavitation, promoting the formation of ${ }^{\circ} \mathrm{OH}$ and increasing the degradation rate of the dye. Besides, larger special surface area can also provide more interfaces to facilitate interaction between the catalyst and dye molecules in catalytic degradation process. ${ }^{51}$ (2) The NPC-58 sample is composed of finer bi-continuous ligaments with a better dispersion, which allows the cavitation bubbles within the interior ligaments to maximize the absorption of acoustic energy. (3) NPC-58 has higher total pore volume $\left(V_{\mathrm{p}}\right)$ $\left(0.072 \mathrm{~cm}^{3} \mathrm{~g}^{-1}\right)$ than NPC-72 $\left(0.048 \mathrm{~cm}^{3} \mathrm{~g}^{-1}\right)$ (exhibited in Table 1), thus providing more channels for diffusion and transportation of $\mathrm{OH}^{, 52}$ which plays a decisive role in the sonocatalytic reaction.

Fig. 5 displays the effects of dye concentration, solution $\mathrm{pH}$, temperature and ultrasonic power on the degradation rate of the NPC-72 sample. To investigate the influence of initial dye concentration on the degradation rate of MO, three different concentrations were selected $\left(10,20,40 \mathrm{mg} \mathrm{L}^{-1}\right)$, while keeping constant solution $\mathrm{pH}(\mathrm{pH}=6)$, temperature $(333 \mathrm{~K})$ and output power $\left(4800 \mathrm{~mW} \mathrm{~cm}^{-2}\right)$. From Fig. $5 \mathrm{a}$, it is observed that $91.2 \%$, $65.8 \%$ and $34.9 \%$ of MO was decomposed after $15 \mathrm{~min}$ for dye concentration of $10,20,40 \mathrm{mg} \mathrm{L}^{-1}$, respectively, the degradation rate of MO decreases obviously with increasing in initial dye concentration. This is because more MO molecules can be adsorbed on the surface of the $\mathrm{Cu}$ ligaments with an increase in dye concentration, which had to be degraded by the constant amount of the reactive radicals $\left({ }^{\circ} \mathrm{OH}\right)$. Furthermore, the increased dye adsorption is expected to reduce the adsorption of hydrogen peroxide $\left(\mathrm{H}_{2} \mathrm{O}_{2}\right)$ on the catalyst surface. Consequently, little $\mathrm{H}_{2} \mathrm{O}_{2}$ is available for sono-Fenton-like process to generate ${ }^{\circ} \mathrm{OH}$, leading to low degradation rate. The results suggest that organic dye with low initial concentration is favored for its sono-catalytic degradation process.

Another significant parameter in sono-Fenton-like process for dye degradation is solution $\mathrm{pH}$. The influence of the $\mathrm{pH}$ of MO solution on its sonocatalytic degradation was studied and the data are shown in Fig. 5b. For these experiments, the initial dye concentration was set to $20 \mathrm{mg} \mathrm{L}^{-1}$, solution temperature and the output power of the ultrasonic generator set to $333 \mathrm{~K}$ and $4800 \mathrm{~mW} \mathrm{~cm}^{-2}$, respectively. It can be seen that the highest degradation efficiency is obtained at the lowest $\mathrm{pH}$ value and the degradation rate of MO decreases with the increase of solution $\mathrm{pH}$. This phenomenon can be attributed to the three points: (1) the surface of the catalyst is positively charged at low
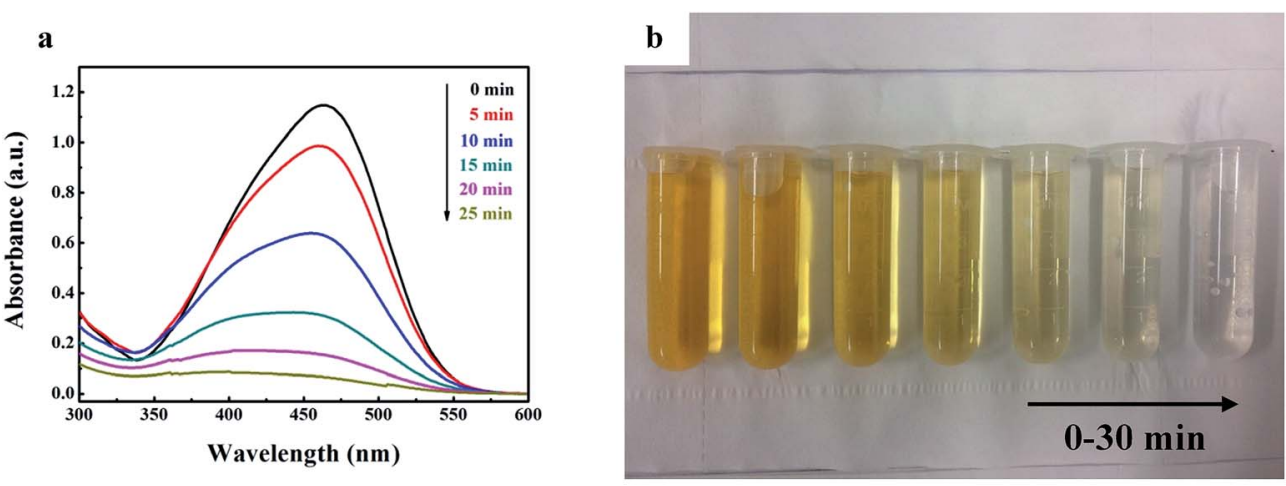

c

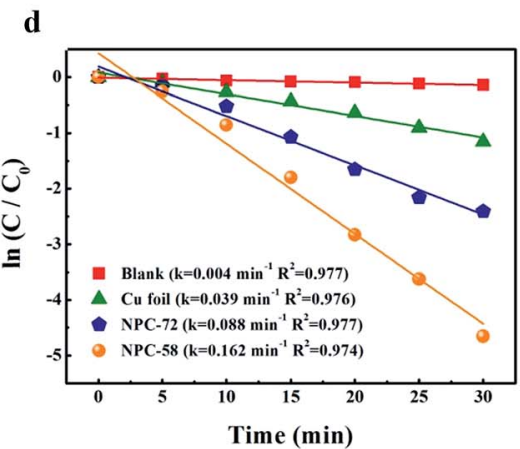

Fig. 4 (a) Time-dependent UV-vis absorption spectra and (b) corresponding photos of MO solution in the presence of NPC-72, (c) sonocatalytic degradation of $\mathrm{MO}$ versus reaction time, (d) linear transform $\ln \left(C / C_{0}\right)$ of the kinetic curves of $\mathrm{MO}$ degradation. 
$\mathbf{a}$

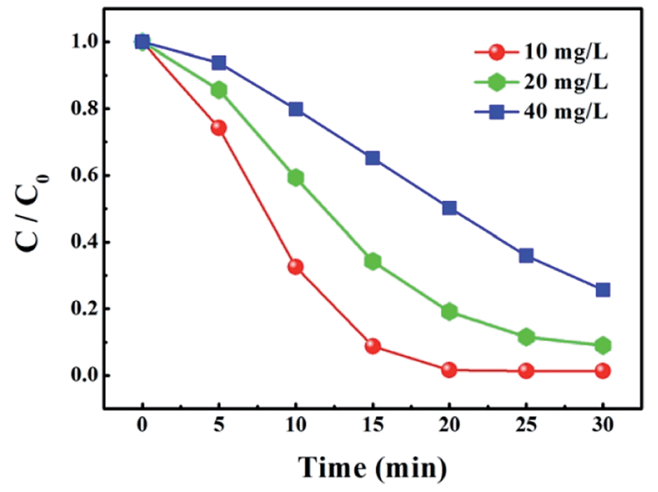

c

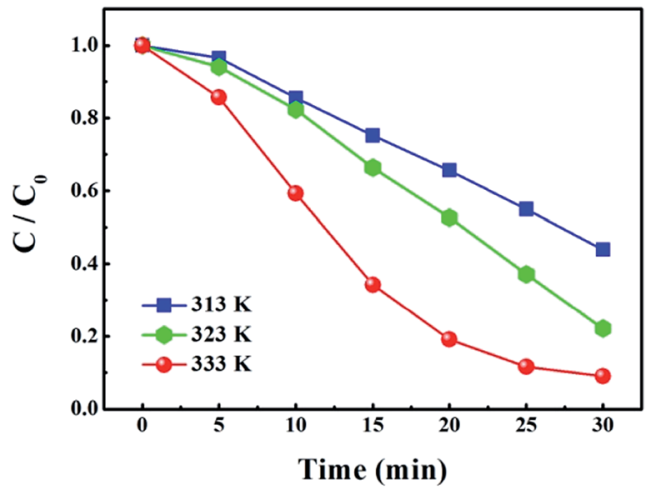

b

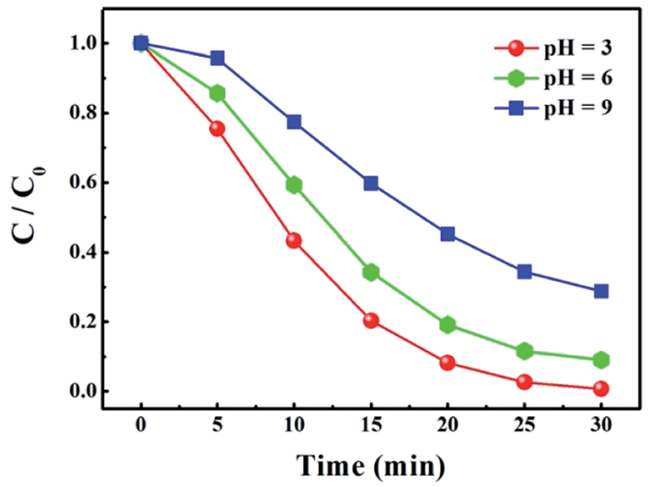

d

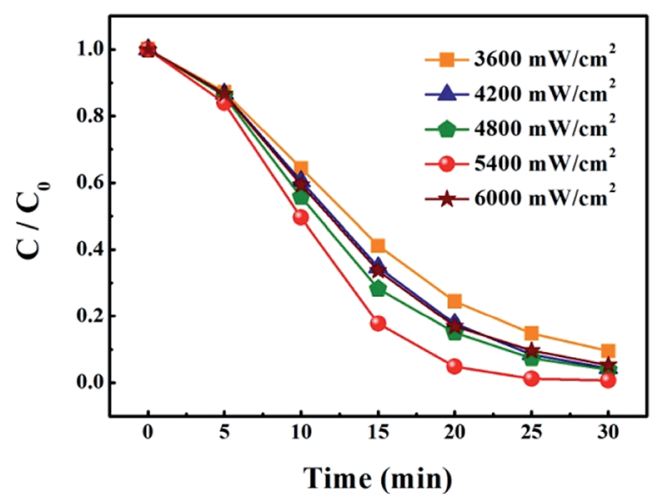

Fig. 5 The effects of (a) dye concentration, (b) $\mathrm{pH}$, (c) temperature and (d) output power on the degradation of MO in the presence of the NPC72 sample.

$\mathrm{pH}$ value, it is easily capable of adsorbing MO which have a negative charge, hence more dye molecules can be degraded by ${ }^{\circ} \mathrm{OH} ;{ }^{47}(2)$ the number of ${ }^{\circ} \mathrm{OH}$ increases on the surface of the catalyst with decreasing of the $\mathrm{pH} ;{ }^{47}(3)$ the ${ }^{\circ} \mathrm{OH} / \mathrm{H}_{2} \mathrm{O}$ redox pair oxidation potential increases from 1.65 to 2.59 versus the normal hydrogen electrode (NHE) with decreasing $\mathrm{pH}$ value, suggesting that the oxidation potential of ${ }^{\circ} \mathrm{OH}$ in acidic medium is much higher than that in alkaline medium. ${ }^{48}$

The temperature is also an important parameter, which can affect dye sono-degradation efficiency significantly. In view of this, the effect of the temperature on the degradation of MO was investigated in Fig. 5c. The temperature of the mixed solution was adjusted over a range of values $(313,323$ and $333 \mathrm{~K})$, and the initial concentration of the dye, solution $\mathrm{pH}$ and the power of the ultrasonic generator were set to $20 \mathrm{mg} \mathrm{L}^{-1}, \mathrm{pH}=6$ and $4800 \mathrm{~mW} \mathrm{~cm}^{-2}$, respectively. The degradation rate of MO can be evaluated to $24.7 \%, 33.6 \%$ and $65.8 \%$ for the temperature at $313,323,333 \mathrm{~K}$, respectively. Obviously, raising temperature led to the increase of the reaction rate. This can be easily understood if considering the relation between reaction rate and temperature, which usually follows the Arrhenius relationship..$^{52,53}$

Ultrasonic power is a very important parameter that affects dye degradation. For this reason, the influence of ultrasonic power on the degradation of MO was investigated. The sonocatalytic degradation experiments were conducted by varying output power from 3600 to $6000 \mathrm{~mW} \mathrm{~cm}^{-2}$ while keeping dye concentration at $20 \mathrm{mg} \mathrm{L}^{-1}$, solution $\mathrm{pH}$ at 6 and temperature at $333 \mathrm{~K}$. Fig. $5 \mathrm{~d}$ shows that the degradation rate of MO increase with enhancing output power of ultrasonic generator ranged from 3600 to $5400 \mathrm{~mW} \mathrm{~cm}{ }^{-2}$. This is because more energy was dissipated to the system by improving output power, which can increase the number of cavitation bubbles. The more presence of collapsing bubbles led to the formation of a greater number of active ${ }^{\circ} \mathrm{OH}$. However, further enhancement

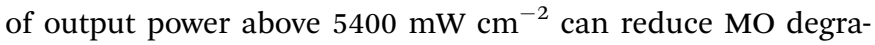
dation rate, and the degradation rate at output power of 6000 $\mathrm{mW} \mathrm{cm}{ }^{-2}$ is even lower than that at $4800 \mathrm{~mW} \mathrm{~cm}^{-2}$. This can be related to the effects of annihilation of ${ }^{\circ} \mathrm{OH}$, which is caused by the increased probability of collision for excessive dosage of ${ }^{\circ} \mathrm{OH}$. The results indicate that there exists an optimum ultrasonic output power for sono-Fenton-like system to degrade MO dye effectively.

The sonocatalytic process of NPC can be explained as a combination of $\mathrm{Cu}$ ligament, $\mathrm{H}_{2} \mathrm{O}_{2}$ and ultrasound (sonoFenton-like process ${ }^{6,48}$ ). Under ultrasonic radiation, the ligaments of NPC will react with $\mathrm{H}_{2} \mathrm{O}_{2}$ to generate hydroxyl radicals $\left({ }^{\circ} \mathrm{OH}\right)$ and $\mathrm{Cu}^{+}$, then the resulting $\mathrm{Cu}^{+}$will further react with $\mathrm{H}_{2} \mathrm{O}_{2}$ to form ${ }^{\circ} \mathrm{OH}$ and $\mathrm{Cu}^{2+}$. Meanwhile, $\mathrm{Cu}^{2+}$ and $\mathrm{Cu}^{+}$will combine with electrons $\left(\mathrm{e}^{-}\right)$in the solution to be reduced back 

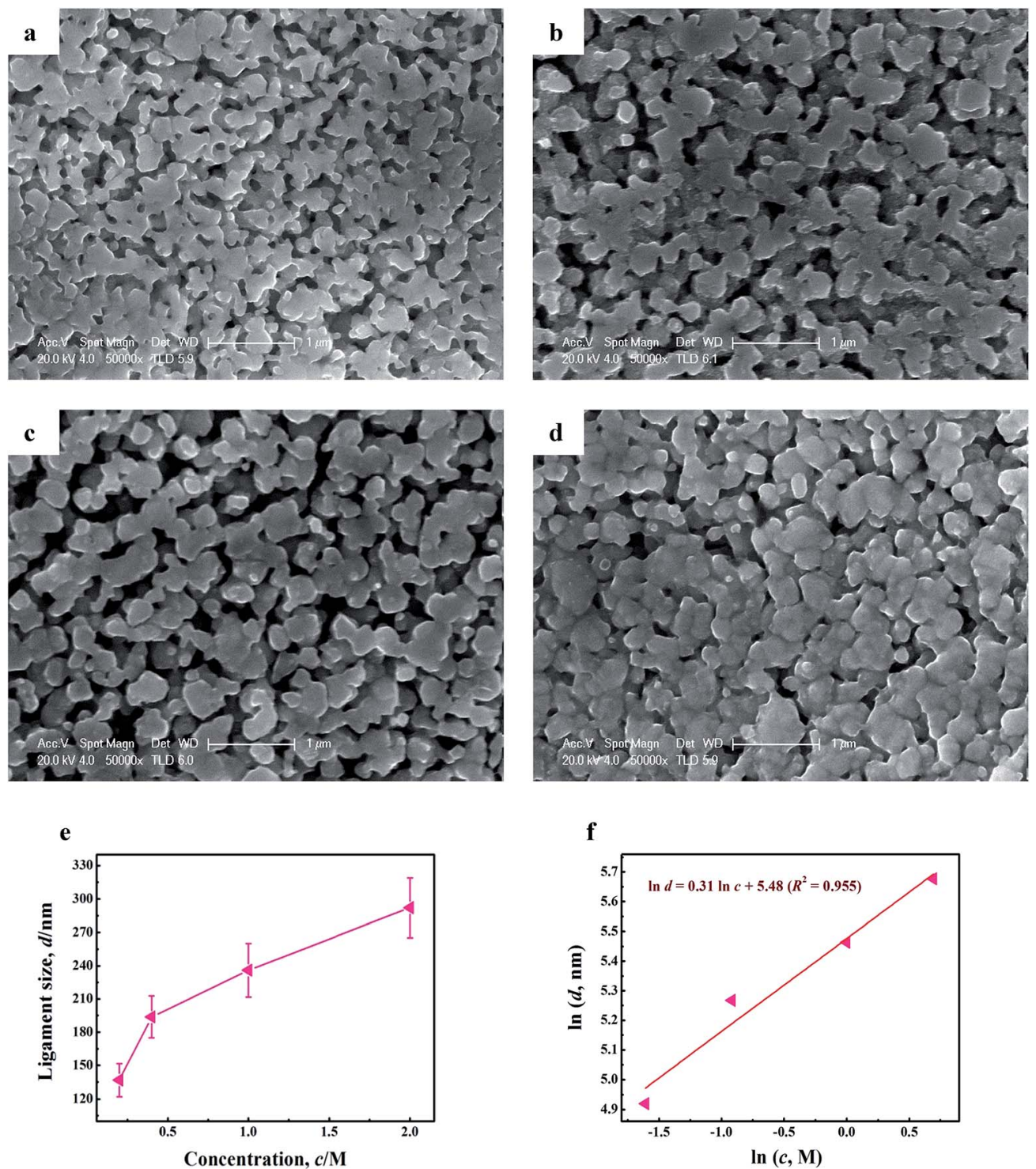

Fig. 6 SEM images of NPC by dealloying $\mathrm{Cu}_{58} \mathrm{Y}_{42}$ metallic glasses at $323 \mathrm{~K}$ for 90 min in different concentration of $\mathrm{H}_{2} \mathrm{SO}_{4}$ aqueous solution: (a) $0.2 \mathrm{M}$; (b) $0.4 \mathrm{M}$; (c) $1 \mathrm{M}$; (d) $2 \mathrm{M}$. (e) Relationship between sulfuric acid concentration (c) and ligament size (d) of NPC by dealloying $\mathrm{Cu}_{58} \mathrm{Y}_{42}$ metallic glasses, (f) plot of In $d$ vs. In $c$.

to $\mathrm{Cu}^{+}$and $\mathrm{Cu}$, respectively, thereby allowing the sono-Fentonlike process to be repeated. Finally, 'OH produced by sonoFenton-like process resolves $\mathrm{MO}$ dye molecules into $\mathrm{H}_{2} \mathrm{O}, \mathrm{CO}_{2}$ and inorganic species. The relevant reaction equations can be described as: ${ }^{6,54,55}$

$$
\begin{gathered}
\left.\left.\mathrm{H}_{2} \mathrm{O}+\right)\right) \text { ) (ultrasound) } \rightarrow{ }^{\cdot} \mathrm{OH}+{ }^{\cdot} \mathrm{H} \\
\left.\left.\mathrm{H}_{2} \mathrm{O}_{2}+\right)\right) \text { ) (ultrasound) } \rightarrow 2^{\cdot} \mathrm{OH}
\end{gathered}
$$

$\mathrm{Cu}$ ligament $\left.\left.+\mathrm{H}_{2} \mathrm{O}_{2}+\mathrm{H}^{+}+\right)\right)$) (ultrasound) $\rightarrow$

$$
\cdot \mathrm{OH}+\mathrm{H}_{2} \mathrm{O}+\mathrm{Cu}^{+}
$$

$\left.\left.\left.\mathrm{Cu}^{+}+\mathrm{H}_{2} \mathrm{O}_{2}+\mathrm{H}^{+}+\right)\right)\right)($ultrasound $) \rightarrow \cdot \mathrm{OH}+\mathrm{H}_{2} \mathrm{O}+\mathrm{Cu}^{2+}(5)$

$$
\mathrm{Cu}^{2+}+\mathrm{e}^{-} \rightarrow \mathrm{Cu}^{+}
$$

$$
\begin{gathered}
\mathrm{Cu}^{+}+\mathrm{e}^{-} \rightarrow \mathrm{Cu} \\
\cdot \mathrm{OH}+\mathrm{MO} \rightarrow \mathrm{H}_{2} \mathrm{O}+\mathrm{CO}_{2}+\text { inorganic species }
\end{gathered}
$$

\section{Relationship between dealloying conditions and ligament size of NPC}

3D bi-continuous NPC with different microstructures have been successfully applied in the sono-catalytic degradation of MO. The one with finer $\mathrm{Cu}$ ligaments and larger special surface area exhibited enhanced sono-Fenton-like catalytic properties. The result implies that NPC with superior catalytic activity can be obtained by tuning alloy composition of amorphous precursors. Nevertheless, adjusting the structure of NPC by methods of changing alloy composition of amorphous precursors is 

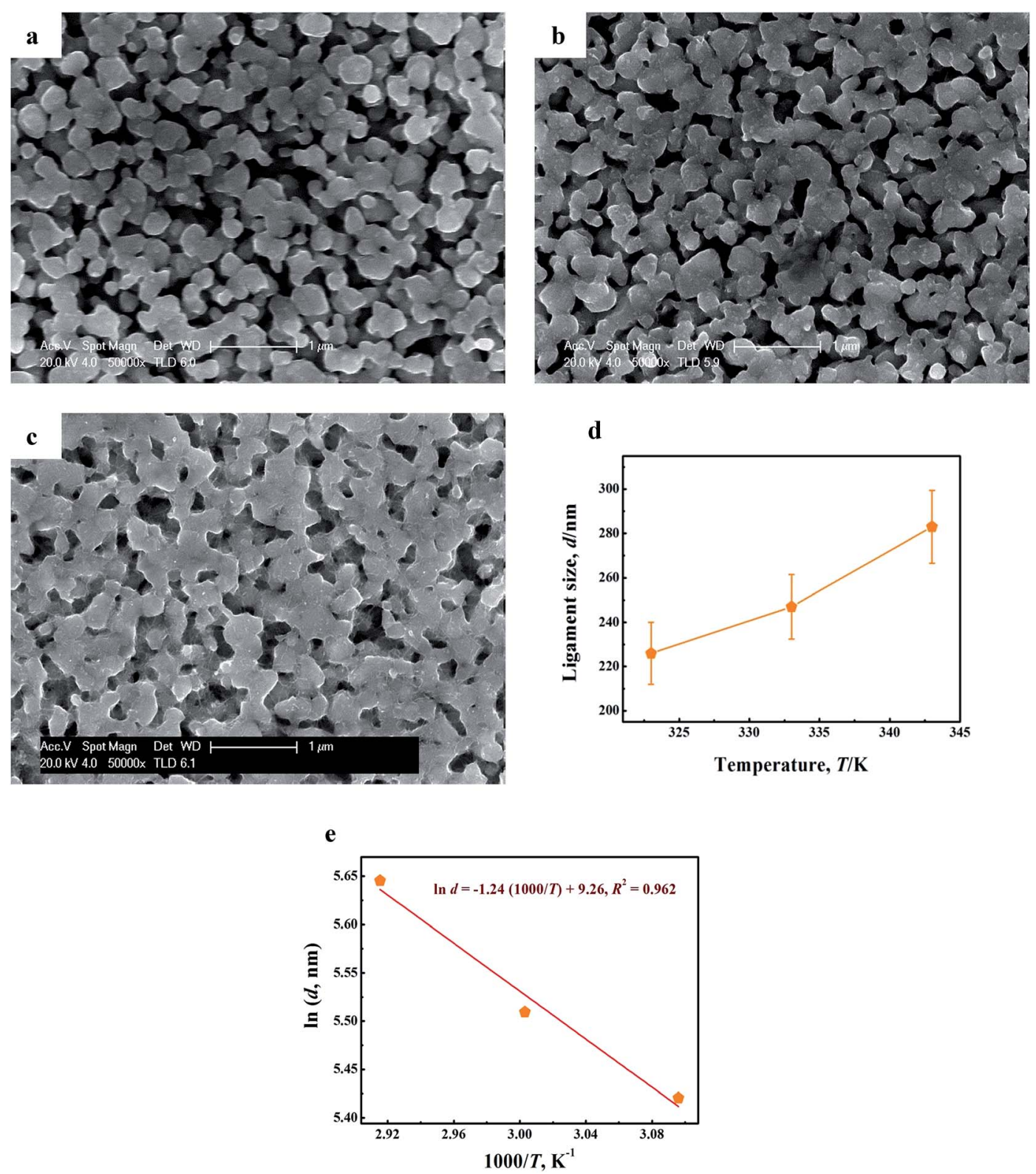

Fig. 7 SEM images of NPC by dealloying $\mathrm{Cu}_{58} \mathrm{Y}_{42}$ metallic glasses in $1 \mathrm{M} \mathrm{H}_{2} \mathrm{SO}_{4}$ aqueous solution for 90 min at various temperatures: (a) $323 \mathrm{~K}$; (b) $333 \mathrm{~K}$; (c) $343 \mathrm{~K}$. (d) Relationship between the temperature ( $T$ ) and ligament size (d) of NPC by dealloying $\mathrm{Cu}_{58} \mathrm{Y}_{42}$ metallic glasses, (e) plot of In $d$ vs. $1000 / T$ for deriving the activation energy $(E)$.

inconvenient because the preparation of glassy precursors can be affected by many uncontrolled factors. ${ }^{56,57}$ Therefore in order to design NPC with more suitable ligament size and higher catalytic activity, the influences of the dealloying conditions (acid concentration, temperature and leaching time) on the ligament size of NPC were evaluated systematically.

Fig. 6a-d depicts the SEM images of the samples by dealloying $\mathrm{Cu}_{58} \mathrm{Y}_{42}$ metallic glasses at $323 \mathrm{~K}$ for 90 min in $\mathrm{H}_{2} \mathrm{SO}_{4}$ aqueous solution with different concentration $(0.2,0.4,1$ and 2 $\mathrm{M})$. An open bi-continuous interpenetrating nanoporous structure was formed on a large scale. It can be seen that the ligament size of NPC can coarsen from 137 to $292 \mathrm{~nm}$ with increase in the acid concentration (shown in Fig. 6e), implying that the morphology of NPC can be tuned by controlling the acid concentration. In addition, a linear correlation between $\ln d$ and $\ln c$ can be established as $\ln d=0.31 \ln c+5.48\left(R^{2}=0.955\right)$ in Fig. 6f, the relationship built will give a constructive reference for the optimization of the ligament size of NPC.

The coarsening behavior of NPC can be described as solidliquid interface diffusion mechanism, similar to the isothermal grain growth in polycrystalline materials. ${ }^{58}$ Hence, the relationship between dealloying conditions (temperature $T$, immersion time $t$ ) and ligament size $d$ of NPC can be modelled with the following equation: ${ }^{59}$

$$
d^{n}=K t D_{\mathrm{s}}
$$



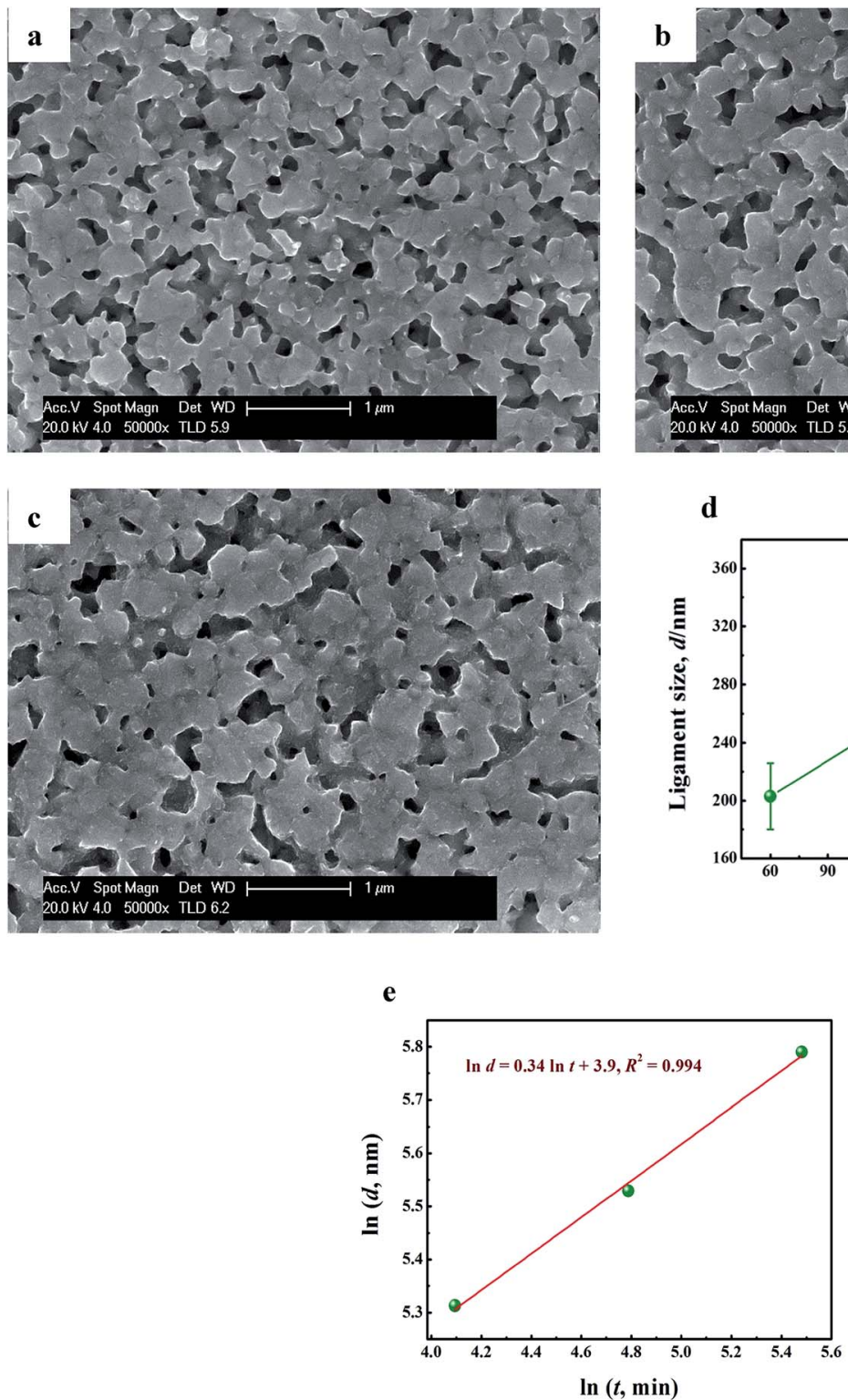

Fig. 8 SEM images of NPC by dealloying $\mathrm{Cu}_{58} \mathrm{Y}_{42}$ metallic glasses in $1 \mathrm{M} \mathrm{H}_{2} \mathrm{SO}_{4}$ aqueous solution at $333 \mathrm{~K}$ for various immersion time: (a) 60 min; (b) $120 \mathrm{~min}$; (c) $240 \mathrm{~min}$. (d) Relationship between the immersion time ( $t$ ) and ligament size (d) of NPC by dealloying $\mathrm{Cu}_{58} \mathrm{Y}_{42}$ metallic glasses, (e) plot of In $d$ vs. In $t$ for deriving the coarsening exponent $(n)$.

where $n$ is the coarsening exponent, $K$ is a constant, $t$ is the immersion time and $D_{\mathrm{s}}$ is the surface diffusivity of $\mathrm{Cu}$ atoms, which can be described by the Arrhenius equation: ${ }^{60,61}$

$$
D_{\mathrm{s}}=D_{0} \exp \left(-\frac{E_{\mathrm{a}}}{R T}\right)
$$

where $D_{0}$ is the diffusion constant, $E_{\mathrm{a}}$ is the activation energy for ligament formation and growth, $R$ is the gas constant and $T$ is the dealloying temperature. By combining eqn (9) and (10), a modified formula can be deduced as follows:

$$
d^{n}=K D_{0} \exp \left(-\frac{E_{\mathrm{a}}}{R T}\right) t
$$

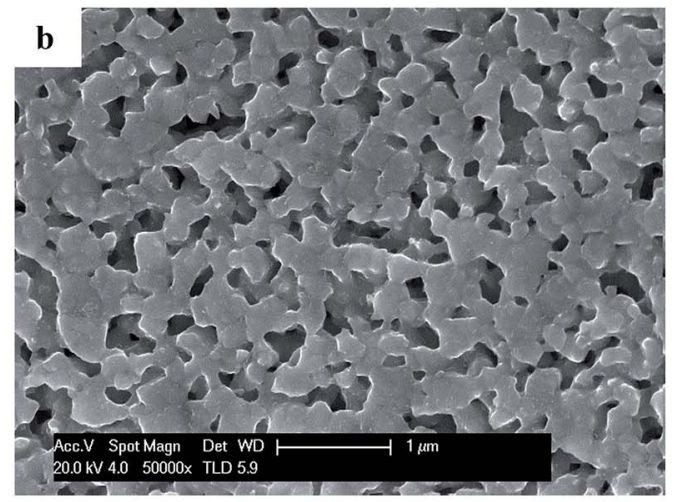

d

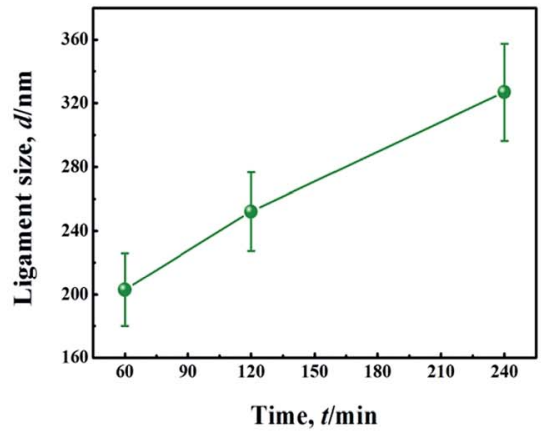


the precursor/solution interface so as to accelerate the ligament growth of NPC. ${ }^{62}$ Moreover, a linear correlation [ln $d=-1.24$ $\left.(1000 / T)+9.26, R^{2}=0.962\right]$ can be fitted in Fig. 7e, which means that the influence of reaction temperature on coarsening behavior of NPC can be well described by eqn (12). According to this fitting, the value of $-E_{\mathrm{a}} / 1000 \mathrm{n} R$ was estimated as -1.24 .

Fig. 8a-c displays the SEM images of the samples by dealloying $\mathrm{Cu}_{58} \mathrm{Y}_{42}$ metallic glasses in $1 \mathrm{M} \mathrm{H}_{2} \mathrm{SO}_{4}$ aqueous solution at $333 \mathrm{~K}$ for various immersion time $(60,120$ and $240 \mathrm{~min})$. Similar bi-continuous nanoporous morphologies of NPC are observed. It is noticed that the ligament coarsening is very apparent (from 203 to $327 \mathrm{~nm}$ ) with the prolongation of leaching time (shown in Fig. 8d), which suggests that the size of ligament strongly depends on the immersion time. Besides, a good linear fitting [ln $\left.d=0.34 \ln t+3.9, R^{2}=0.994\right]$ was observed in Fig. 8e, thus confirming that the effect of leaching time on ligament growth of NPC can be also described by the diffusion growth model [eqn (12)]. The coarsening exponent $n$, directly derived by plotting the $\ln d v s$. $\ln t$ curves (the reciprocal of the slope in Fig. 8e), was calculated to be 2.941. Combined with previous fitting data $\left(-E_{\mathrm{a}} / 1000 n R\right)$ in Fig. 7e and the values of $n$, the activation energy $\left(E_{\mathrm{a}}\right)$ was deduced to be $30.3 \mathrm{~kJ} \mathrm{~mol}^{-1}$. The value is too much lower than that of $\mathrm{Al}-\mathrm{Cu}$ alloy system in $\mathrm{NaOH}$ solution $\left(145.3 \mathrm{~kJ} \mathrm{~mol}^{-1}\right),^{63}$ indicating that $\mathrm{Cu}-\mathrm{Y}$ alloy system has great advantages for fabricating NPC rapidly. For $\mathrm{Cu}_{58} \mathrm{Y}_{42}$ precursors, lower $E_{\text {a }}$ can be ascribed to high corrosion activity of the less noble element in electrolytes (the activity of $\mathrm{Y}$ atoms in $\mathrm{H}_{2} \mathrm{SO}_{4}$ aqueous solution is much higher than that of $\mathrm{Al}$ atoms in $\mathrm{NaOH}$ solution). Based on the above results, it can be seen that the relationships established between the dealloying conditions and ligament size of NPC provides abundant references for the optimization of the morphology of NPC, which is beneficial to the synthesis of NPC with more excellent sono-catalytic activity.

\section{Conclusions}

In this work, uniform nanoporous copper (NPC) was developed via chemically dealloying $\mathrm{Cu}-\mathrm{Y}$ binary metallic glasses. The NPC samples not only exhibited 3D bi-continuous interpenetrating pore-to-ligament nanostructure, but also were found to be highly active for MO degradation. It should be noticed that the NPC-58 sample presented much better sono-catalytic efficiency $\left(k=0.162 \mathrm{~min}^{-1}\right)$ compared with NPC-72 $\left(k=0.088 \mathrm{~min}^{-1}\right)$. This result can be caused by larger specific surface area $\left(3.84 \mathrm{~m}^{2} \mathrm{~g}^{-1}\right)$, finer bi-continuous $\mathrm{Cu}$ ligaments $(237 \mathrm{~nm})$ and higher total pore volume $\left(0.072 \mathrm{~cm}^{3} \mathrm{~g}^{-1}\right)$ of NPC- 58 . The sonoFenton-like process of NPC with desired microstructure has shown great potential in treating dye wastewater. By controlling dealloying conditions (acid concentration, reaction temperature and immersion time) of $\mathrm{Cu}_{58} \mathrm{Y}_{42}$ amorphous precursors, the ligament sizes of the resulting NPC were tuned between 137 and $327 \mathrm{~nm}$. The result provides a guide for further designing NPC with more suitable ligaments and higher catalytic activity.

\section{Conflicts of interest}

There are no conflicts to declare.

\section{Acknowledgements}

This work was supported by the National Natural Science Foundation of China (Grant No. 51671056) and Jiangsu key laboratory for advanced metallic materials (Grant No. BM2007204).

\section{References}

1 H. B. Zhang, C. S. Wei, Y. Y. Huang and J. Wang, Ultrason. Sonochem., 2016, 30, 61-69.

2 R. Bhavani and A. Sivasamy, Ecotoxicol. Environ. Saf., 2016, 134, 403-411.

3 Y. Jiang, Y. Sun, H. Liu, F. Zhu and H. Yin, Dyes Pigm., 2008, 78, 77-83.

4 H. Zhao, G. M. Zhang and Q. L. Zhang, Ultrason. Sonochem., 2014, 21, 991-996.

5 J. Wang, T. Ma, Z. H. Zhang, X. D. Zhang, Y. F. Jiang and Z. J. Pan, Desalination, 2006, 195, 294-305.

6 C. K. Wang and Y. H. Shih, Sep. Purif. Technol., 2015, 140, 612.

7 C. A. Orge, J. J. M. Orfao, M. F. R. Pereira, A. M. Duarte de Farias and M. A. Fraga, Chem. Eng. J., 2012, 200-202, 499505.

8 K. S. Suslick, S. J. Doktycz and E. B. Flint, Ultrasonics, 1990, 28, 280-290.

9 C. Cai, Z. Zhang, J. Liu, N. Shan, H. Zhang and D. D. Dionysiou, Appl. Catal., B, 2016, 182, 456-468.

10 R. K. Joshi and P. R. Gogate, Ultrason. Sonochem., 2012, 19, 532-539.

11 M. A. Matouq, Z. A. Al-Anber, T. Tagawa, S. Aljbour and M. Al-Shannag, Ultrason. Sonochem., 2008, 15, 869-874.

12 N. Daneshvar, S. Aber, M. S. Seyed Dorraji, A. R. Khataee and M. H. Rasoulifard, Sep. Purif. Technol., 2007, 58, 91-98.

13 R. Saraf, C. Shivakumara, S. Behera, H. Nagabhushana and N. Dhananjaya, Spectrochim. Acta, Part A, 2015, 136, 348-355.

14 A. Turki, C. Guillard, F. Dappozze, Z. Ksibi, G. Berhault and H. Kochkar, Appl. Catal., B, 2015, 163, 404-414.

15 M. Zhou, H. Yang, T. Xian, R. S. Li, H. M. Zhang and X. X. Wang, J. Hazard. Mater., 2015, 289, 149-157.

16 Y. L. Min, K. Zhang, Y. C. Chen and Y. G. Zhang, Ultrason. Sonochem., 2012, 19, 883-889.

17 Y. Y. Huang, H. B. Zhang, C. S. Wei, G. S. Li, Q. Wu and J. Wang, Sep. Purif. Technol., 2017, 172, 202-210.

18 S. Kaur and V. Singh, Ultrason. Sonochem., 2007, 14, 531-537. 19 C. H. Wang, Y. T. Lin, C. K. Chang and N. Liu, Ultrason. Sonochem., 2013, 20, 970-977.

20 R. Vinu and G. Madras, Environ. Sci. Technol., 2009, 43, 473479.

21 S. Chong, G. M. Zhang, N. Zhang, Y. C. Liu, J. Zhu and T. Huang, Ultrason. Sonochem., 2016, 32, 231-240.

22 Z. Wu, G. Cravotto, M. Adrians, B. Ondruschka and W. Li, Ultrason. Sonochem., 2015, 27, 148-152.

23 A. Hassani, A. Khataee, S. Karaca, C. Karaca and P. Gholami, Ultrason. Sonochem., 2017, 35, 251-262.

24 K. Suslick, Science, 1990, 247, 1439-1445.

25 E. B. Flint and K. S. Suslick, Science, 1991, 253, 1397-1399. 
26 O. Moumeni and O. Hamdaoui, Ultrason. Sonochem., 2012, 19, 404-409.

27 A. Khataee, M. Sheydaei, A. Hassani, M. Taseidifar and S. Karaca, Ultrason. Sonochem., 2015, 22, 404-411.

28 C. Petrier, M. Lamy, A. Francony, A. Benahcene and B. David, J. Phys. Chem., 1994, 98, 1051-1057.

29 T. Tuziuti, K. Yasui, M. Sivakumar and Y. Iida, J. Phys. Chem. A, 2005, 109, 4869-4872.

30 Y. Wu, L. Song, S. Zhang, X. Wu, S. Zhang, H. Tian and J. Ye, Catal. Commun., 2013, 37, 14-18.

31 H. Sekiguchi and Y. Saita, J. Chem. Eng. Jpn., 2001, 34, 10451048.

32 E. Neyens and J. Baeyens, J. Hazard. Mater., 2003, 98, 33-50.

33 G. C. Bond and D. T. Thompson, Catal. Rev.: Sci. Eng., 1999, 41, 319-388.

34 T. You, O. Niwa, M. Tomita and S. Hirono, Anal. Chem., 2003, 75, 2080-2085.

35 D. Kramer, R. N. Viswanath and J. Weissmuller, Nano Lett., 2004, 4, 793-796.

36 J. R. Weissmueller, N. Viswanath, D. Kramer, P. Zimmer, R. Wuerschum and H. Gleiter, Science, 2003, 300, 312-315.

37 S. H. Joo, S. J. Choi, K. J. Kwa and Z. Liu, Nature, 2001, 412, 169-172.

38 A. Wittstock, V. Zielasek, J. Biener, C. M. Friend and M. Baumer, Science, 2010, 327, 319-322.

39 J. Erlebacher, J. Electrochem. Soc., 2004, 151, C614-C626.

40 J. S. Yu, Y. Ding, C. X. Xu, A. Inoue, T. Sakurai and M. W. Chen, Chem. Mater., 2008, 20, 4548-4550.

41 A. Inoue, Acta Mater., 2000, 48, 263-279.

42 P. Rizzi, F. Scaglione and L. Battezzati, J. Alloys Compd., 2014, 586, S117-S120.

43 Y. Jin, R. Li and T. Zhang, Intermetallics, 2015, 67, 166-170. 44 Z. H. Dan, F. X. Qin, S. Yamaura, Y. Sugawara, I. Muto and N. Hara, J. Alloys Compd., 2013, 581, 567-572.

45 N. Wang, Y. Pan, T. Lu, X. Z. Li, S. K. Wu and J. L. Wu, Appl. Surf. Sci., 2017, 403, 699-706.
46 X. K. Luo, R. Li, L. Huang and T. Zhang, Corros. Sci., 2013, 67, 100-108.

47 J. Wang, B. D. Guo, X. D. Zhang, Z. H. Zhang, J. T. Han and J. Wu, Ultrason. Sonochem., 2005, 12, 331-337.

48 A. Khataee, P. Gholami, B. Vahid and S. W. Joo, Ultrason. Sonochem., 2016, 32, 357-370.

49 G. Elango and S. M. Roopan, J. Photochem. Photobiol., B, 2016, 155, 34-38.

50 V. Scuderi, G. Amiard, S. Boninelli, S. Scalese, M. Miritello and P. M. Sberna, Mater. Sci. Semicond. Process., 2016, 42, 89-93.

51 S. Kumar and A. K. Ojha, J. Alloys Compd., 2015, 644, 654662.

52 Z. Deng, C. Zhang and L. Liu, Intermetallics, 2014, 52, 9-14.

53 X. F. Wang, Y. Pan, Z. R. Zhu and J. L. Wu, Chemosphere, 2014, 117, 638-643.

54 P. Vaishnave, A. Kumar, R. Ameta, P. B. Punjabi and S. C. Ameta, Arabian J. Chem., 2014, 7, 981-985.

55 J. L. Zhang, F. Chen, B. Z. Tian and L. Z. Wang, Photocatalysis, East China University of Science and Technology Press, Shanghai, 2012.

56 K. Georgarakis, Y. Li, M. Aljerf, D. Dudina, A. LeMoulec and A. R. Yavari, J. Alloys Compd., 2010, 504, S14-S17.

57 Y. F. Ma, P. Yu and L. Xia, Mater. Des., 2015, 85, 715-718.

58 J. E. Burke, Trans. AIME, 1949, 180, 73-91.

59 L. H. Qian and M. W. Chen, Appl. Phys. Lett., 2007, 91, 083105.

60 E. G. Seebauer and C. E. Allen, Prog. Surf. Sci., 1995, 49, 265330.

61 J. M. Dona and J. Gonzalez-Velasco, J. Phys. Chem., 1993, 97, 4714-4719.

62 Y. Jin, R. Li, L. Zuo and T. Zhang, J. Alloys Compd., 2017, 695, 1600-1609.

63 W. B. Liu, S. C. Zhang, N. Li, J. W. Zheng and Y. L. Xing, Microporous Mesoporous Mater., 2011, 138, 1-7. 